\title{
Simultaneous lithospheric-atmospheric signals of acoustic emission at "Karymshina" site in Kamchatka
}

\author{
Igor Larionov ${ }^{1, *}$, Yuriy Marapulets ${ }^{1}$, and Mikhail Mishchenko ${ }^{1}$ \\ ${ }^{1}$ Institute of Cosmophysical Research and Radio Wave Propagation FEB RAS, Mirnaya, 7, Paratunka, \\ Kamchatkskiy kray, 684034, Russia
}

\begin{abstract}
We present the results of complex lithospheric-atmospheric investigations of acoustic emission in a seismically active region (Kamchatka peninsula). A laser strainmeter-interferometer, a geophone, a wide-band acoustic system and a microbarometer, installed at Karymshina site (IKIR FEB RAS), are used in the monitoring. Rock deformation, acoustic emission in the near-surface rocks and in the atmosphere by the ground surface are under the consideration. Moreover, we suggest a method to detect acoustic signals recorded simultaneously in the near-surface rocks and in the atmosphere by the ground surface. The method consists in filtration of acoustic signals from the sensors at different frequency sub-ranges from fractions to the first hundreds of hertz followed by detection and accumulation of on 1-second interval. We analyze the data from September 2016 to December 2020. Examples of records of simultaneous acoustic signals in rocks and in the atmosphere are illustrated. The investigation is topical for the construction of a model of lithosphere-atmosphere interaction in a seismically active region.
\end{abstract}

\section{Introduction}

At the present time, one the most important directions in Geophysics is the construction of models for lithosphere-atmosphere-ionosphere-magnetosphere interaction. Acoustic waves, propagating in the earth crust-atmosphere system, play an important role in such an interaction. They can be excited during different processes of natural and anthropogenic character and are accompanied by intensive energy release [1]. Those may be different kinds of earth surface movements during a seismo-tectonic process [2-4], volcano eruptions [5, 6], explosions [7-9], and operation of powerful technical equipment and mechanisms, in particular, thumpers $[10,11]$. At present there are experimental proves for the output of acoustic waves, excited by the near-surface sources, into the atmosphere and ionosphere (for example, [1114]). Atmospheric-lithospheric interaction manifests the most evidently in the seismically active region at the final stage of earthquake preparation $[15,16]$. High interest to the joint consideration of seismoacousic wave processes is determined by the fact that low-frequency acoustic waves are capable of propagating at long distances and reach ionospheric heights under favorable conditions (low attenuations and scattering, weak refraction in the atmosphere) [17]. Owing to that, they play a significant role in energy transfer between geospheres and

\footnotetext{
*e-mail: igor@ikir.ru
} 
may be one of the reasons of earthquake precursor manifestation in the atmosphere and ionosphere.

Investigations of geoacoustic emission dynamics at the final stage of earthquake preparation have been carried out at IKIR FEB RAS since 1999. During the investigation the acoustic-emission effect was discovered. It consists in the increase of geoacoustic emission intensity in the frequency range from hundreds of hertz to the first tens of kilohertz during rock massive deformation rate increase [18-20]. It was shown that the effect manifests the most clearly in the earthquake preparation zone 1-3 days before a seismic event and is generated by geomechanics stress field change as a result of the transformation: stress near-surface rock deformation.

One of the further directions of the investigation in this area is the consideration and confirmation of the possibility of output of the acoustic emission preceding earthquakes into the atmosphere. In view of this, complex lithospheric-atmospheric investigations of acoustic emission have been carried out at IKIR FEB RAS since 2015. To make such monitoring, we use a laser strainmeter-interferometer, a geophone, wide-band acoustic system and a microbarometer. Rock deformation, acoustic emission in the near-surface rocks and in the atmosphere by the ground surface are under the study.

Initially, in the course of the investigations it was shown that $P$ and $S$ waves from earthquakes enter the atmosphere and are recorded over the ground surface [21]. It was shown in the paper [22] that during deformation disturbances in rocks with relative deformations of $10^{-5}-10^{-7}$, geoacoustic signals of pulse nature with the frequency of units-tens of $\mathrm{Hz}$ occur at the observation site. They may pass the earth-atmosphere boundary and be recorded in the air by the ground surface. In this paper we investigate occurrences of such signals over a long time period from September 2016 to December 2020.

\section{Equipment and observation method}

The investigations are carried out at Karymshina site, IKIR FEB RAS (52.83 N, 158.13 E), located in the zone of different-rank tectonic faults. A laser strainmeter-interferometer is used to record deformations. The measuring base length is $18 \mathrm{~m}$ and the sensitivity is $10^{-11}$. When organizing deformation measurements, we chose the open-type scheme, i.e. without light guides and without weather effect compensation. Such a scheme imposed some restrictions on measurement accuracy. When recording relative deformations, it is not less than $10^{-8}$. We should note that to investigate the local deformation process in sedimentary rocks, such accuracy turned to be enough $[19,23]$. We consider rock relative deformation $\varepsilon$.

To record low-frequency geoacoustic signals at the measurement point of ground surface deformations, a three-component piezoceramic geophone is mounted on the streinmeter optical bench end surface [24]. It converts acoustic signals into electric voltage proportional to oscillatory acceleration in the frequency range of $0.2-400 \mathrm{~Hz}$. The geophone was arranged in such a way that one of the orthogonal components of the recorded acoustic signal ( $\mathrm{Z}$ component) coincides with the strainmeter measurement axis direction, and $\mathrm{X}$ component is vertical [25].

A system of four piezoceramic hydrophones is used for high-frequency geoacoustic measurements. They are installed in artificial reservoirs with the sizes of $1 \times 1 \times 1 \mathrm{~m}^{3}$ and are oriented vertically downwards. We consider wide-band data in the frequency range of $0.1 \mathrm{~Hz}-$ $11 \mathrm{kHz}$ and the signals filtered in seven sub-ranges of 0.1-10, 30-60, 70-200, 200-600, 600-2000, 2000-6500, 6500-11000 Hz followed by detection and accumulation on 1-second interval for each of 4 channels [19]. Three hydrophones (№2, 3, 4) form a triangle with the side of $5 \mathrm{~m}$ around the mount for the strainmeter with a reflector. The hydrophone №1 is installed about $50 \mathrm{~m}$ from this mount. 
A microbarometer ISGM-03M, produced by the scientific-technical center "Geofizicheskie izmereniya", Novosibirsk, is used to measure atmospheric acoustic emission. It was installed 4 meters away from the strainmeter in a pit, which is $0.5 \mathrm{~m}$ deep and is covered from precipitation. The microbarometer ISGM-03M is aimed at converting air pressure variations into electric signal in the operating frequency band from 0.02 to $100 \mathrm{~Hz}$ in the amplitude range from 0.001 to $100 \mathrm{~Pa}$. The mode of functioning is based on the measurement of elastic membrane shift relatively a fixed electrode from air pressure variation effect by displacement capacitance sensor [21].

The important peculiarity of the experiment is the fact that the sensors, installed not far from each other, are covered by a three-meter snow layer in winter-spring time that provides temperature stabilization. To analyze meteorological factor effect, we used the data from a weather station located $20 \mathrm{~m}$ from the strainmeter. We should note that wind velocity makes the greatest impact on the instrument reading. It manifests as signal amplitude oscillation amplification.

Ground surface deformations, geoacoustic emission of near-surface sedimentary rocks and atmospheric acoustic emission are recorded by a hardware-software complex described in detail in [26]. ADC sampling frequency is $1 \mathrm{kHz}$ (48 kHz for high-frequency geoacoustic measurements). The important part of preliminary processing of the data from different recording systems is time synchronization. Owing to the installed standard time signal system including a high-accuracy GPS receiver and the same sampling frequency, we succeeded to synchronize the data series with the accuracy up to a millisecond.

At the stage of preliminary processing of the data from the microbarometer and the geophone, the recorded signals were filtered digitally applying Butterworth band filters with the passing frequency in the ranges of $0-0.13,0.13-0.6,0.6-5,5-10,10-30,30-49,52-99 \mathrm{~Hz}$ with further detection and accumulation on 1-second interval. When analyzing the data, in order to exclude the cases of the disturbances associated with earthquakes, all the detected simultaneous acoustic signals were compared with the data from regional earthquake catalogue of Kamchatka Branch of Geophysical Survey RAS. When such disturbances were detected, they were not taken into consideration.

The signals were analyzed simultaneously from four observation systems, thus it was necessary to chose a key time series relatively which all the rest of the data were considered. The microbarometer data were chosen as such a series. When these data were considered in detail and compared with meteorological parameters, it was discovered that wind velocity makes the greatest impact on the signal in the frequency range of $0-0.13 \mathrm{~Hz}, 0.13-0.6$ and $0.6-5$ (fig.1).

Preliminary analysis and comparison of the signals showed that sometimes sudden pulse jumps of signal amplitude are recorded in the microbarometer data in the frequency ranges of $0.6-5,5-10 \mathrm{~Hz}$ and $10-30 \mathrm{~Hz}$ (fig.2). The disturbances in the ranges of 10-30, 30-49 Hz and $52-99 \mathrm{~Hz}$ in the geophone data correspond to them the most brightly (fig.3(a,b,c)). In this case, disturbances in geophone data manifest in X component the most. At that moment in high-frequency geoacoustic system data, the disturbances are recorded by the hydrophone №1 at the frequency ranges of 0.1-10, 30-60, 70-200 and 200-600 Hz (fig.4(a)). Deformations generating those signals are recorded both in wide-band data of high-frequency acoustic system and by the strainmeter-interferometer (fig.4(b)). 


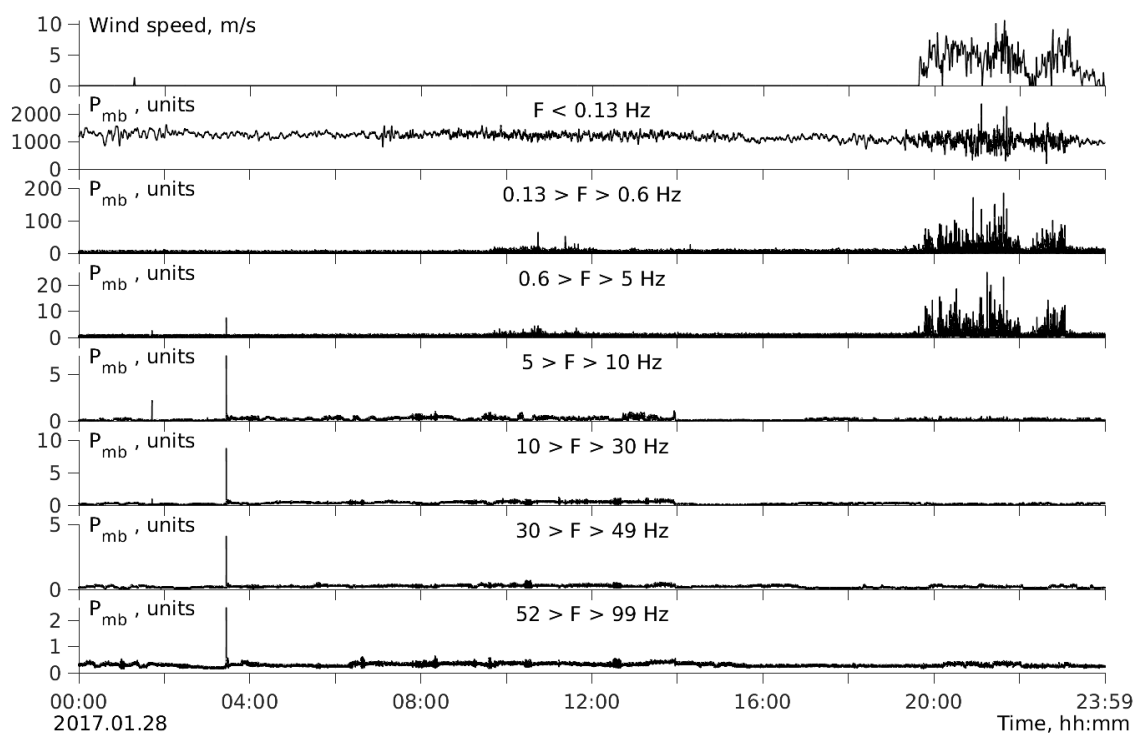

Figure 1: Example of wind effect on atmospheric acoustic signal variations $P_{m b}$ recorded by the microbarograph in different frequency sub-ranges

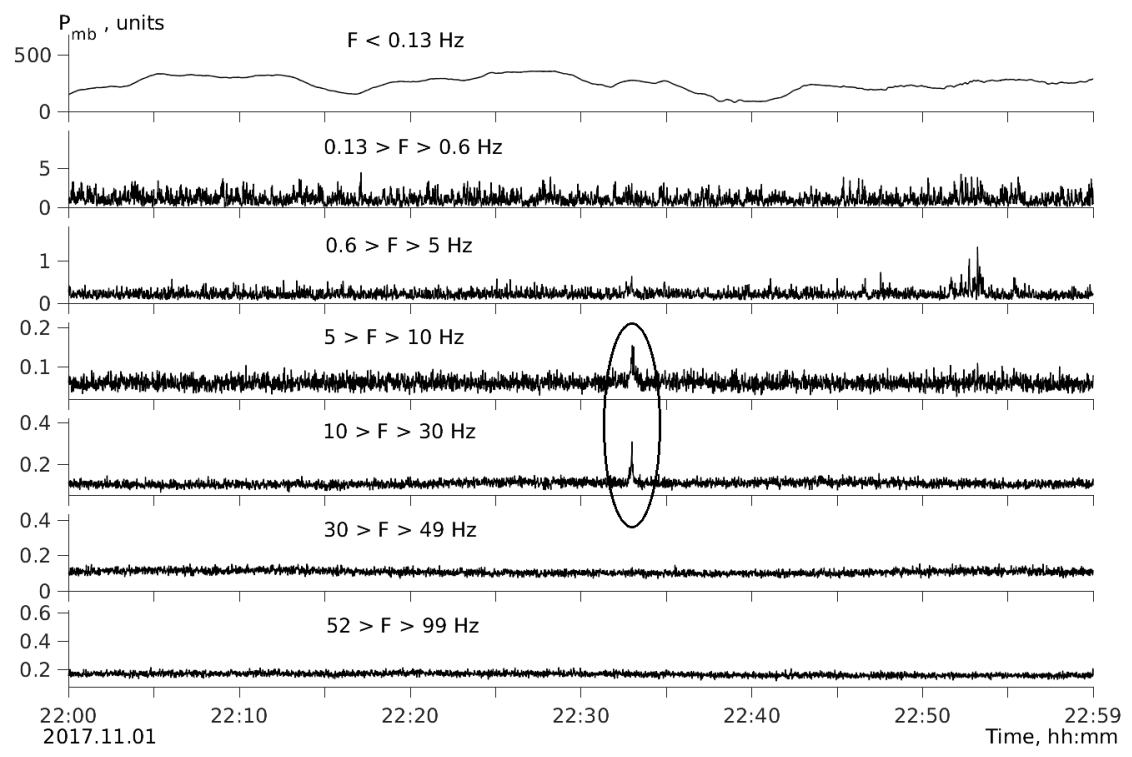

Figure 2: Atmospheric acoustic signal variations Pmb recorded by the microbarograph from 22:00 to 23:00 UT on November 1, 2017. Ellipse shows the amplitude pulse jump 


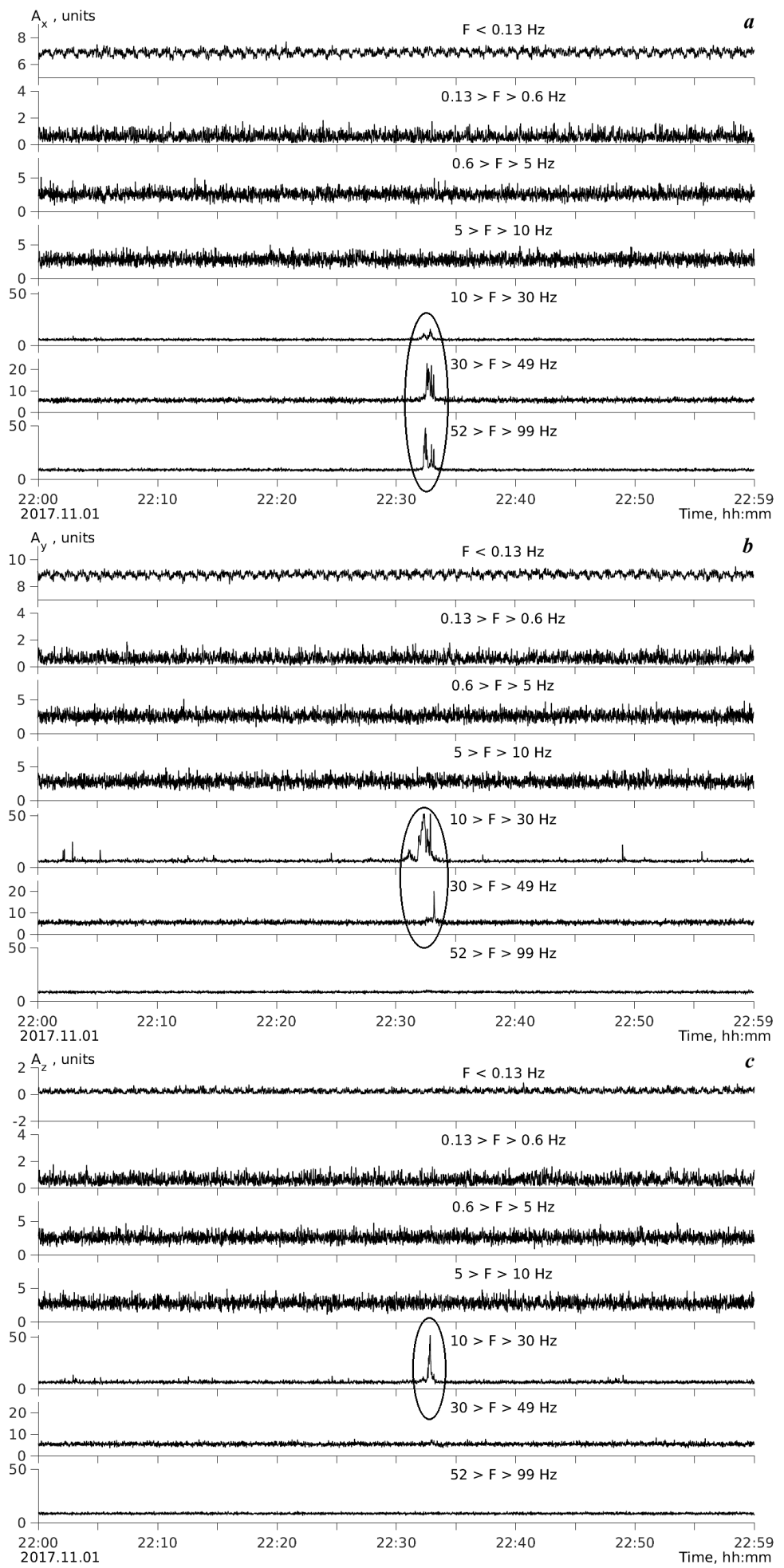

Figure 3: Geoacoustic signal variations $A_{x}, A_{y}, A_{z}$ recorded by the three-component geophone from 22:00 to 23:00 UT on November 1, 2017. The components: X (a), Y (b), Z (c). Ellipses show amplitude pulse jump which was also recorded in microbarometer signal (Fig. 2) 


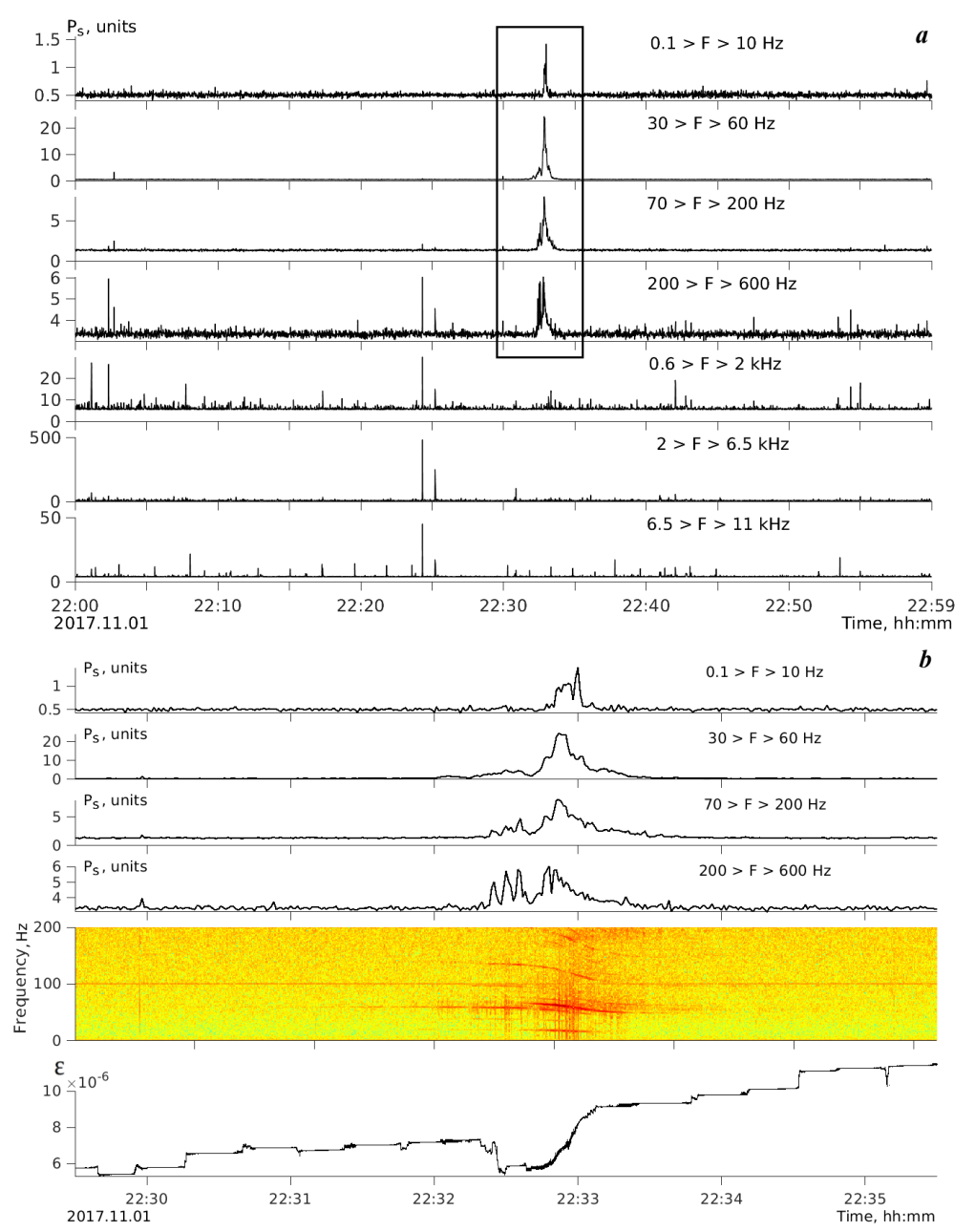

Figure 4: Geoacoustic signal variations $P_{s}$ recorded by the hydrophone №1 of high-frequency geoacoustic system from 22:00 to 23:00 UT on November 1, 2017 (a). A record fragment of amplitude pulse jump of the acoustic signal which was also recorded in microbarometer and geophone signals (Fig. 2,3) is marked by a rectangle. Development of the selected record fragment of amplitude pulse jump of acoustic signal $P_{s}$ in four frequency sub-ranges, its spectrogram and rock relative deformation $\varepsilon$ recorded by the laser strainmeter-interferometer (b)

Thus, in the further analysis we considered:

- microbarometer data in the frequency ranges of $5-10 \mathrm{~Hz}, 10-30 \mathrm{~Hz}$ (the range of $0.6-5$ was not used due to strong wind effect);

- geophone data in the frequency ranges of $10-30,30-49 \mathrm{~Hz}$ and $52-99 \mathrm{~Hz}$;

- high-frequency geoacoustic system data (hydrophone №1) in the frequency ranges of 0.110, 30-60, 70-200 and 200-600 Hz;

- relative deformations recorded by the laser strainmeter-interferometer. 


\section{Observation results}

We analyzed acoustic data for the period from September 2016 to December 2020. It was found out that during that period sudden jumps of signal amplitude were sometimes recorded simultaneously by all observation systems. Analysis of these signal time features did not discover any clear regularities. Such signals occurred during the whole period of observations in different seasons and at different time of a day. That fact almost excludes their man-caused nature as they would manifest stronger during day time. Moreover, since September 2016 until August 2019 the power for the equipment at Karymshina site was supplied by a diesel electric generator. In September 2019 a sun electric station was installed. However, that turn to noiseless power system did not affect the character of those acoustic signal occurrences. Fig.5,6,7 show the examples of simultaneous records of acoustic signal disturbances in the near-surface rocks and in the atmosphere by the ground surface during different time periods.

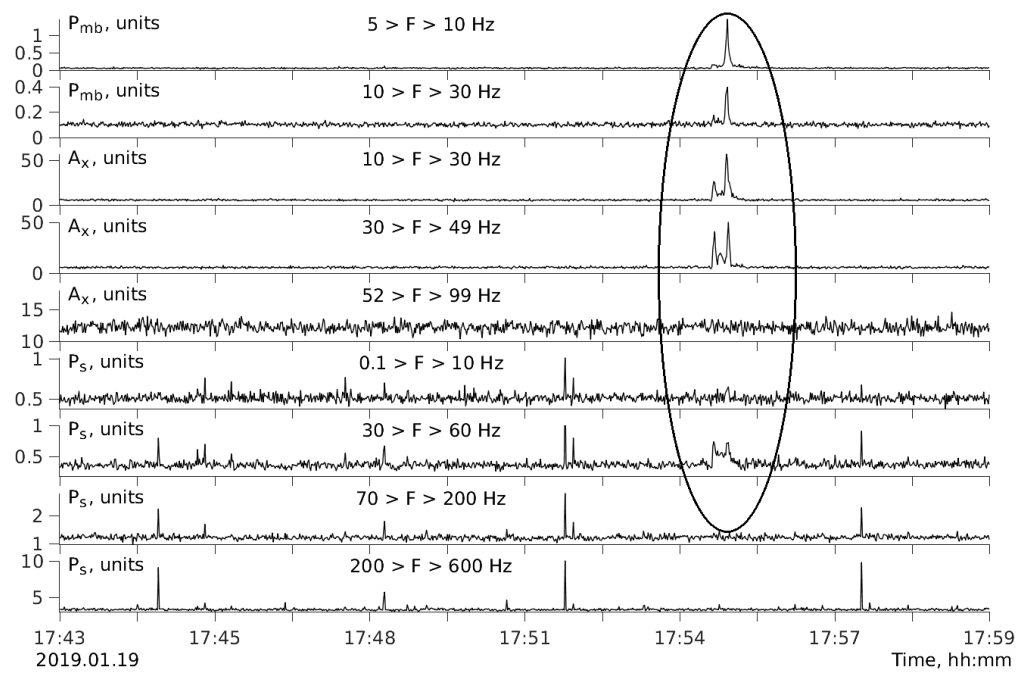

Figure 5: Atmospheric acoustic signal variations $P_{m b}$ recorded by the microbarometer, geoacoustic signal $A_{x}$ recorded by the geophone (X component), geoacoustic signal $P_{s}$ recorded by the hydrophone №1 of high-frequency geoacoustic system from 17:43 to 17:59 UT on January 19, 2019. Ellipse shows the simultaneous amplitude jump.

Fig.5 illustrates a acoustic signal variations by the microbarometer, the geophone and by the high-frequency geoacoustic signal early in the morning (at about 5:00 LT) in winter 2019. In this case the pulse signal was detected in all analyzed ranges of the microbarometer and the geophone. The high-frequency geoacoustic system recorded the signal in the ranges of $0.1-10 \mathrm{~Hz}$ and 30-60 Hz (hydrophone №1).

Fig. 6 shows a acoustic signal variations by the microbarometer, the geophone and by the high-frequency geoacoustic signal in spring 2019. In this case, the pulse signal was detected in the ranges of $5-10 \mathrm{~Hz}$ and $10-30 \mathrm{~Hz}$ of the microbarometer, in the ranges of $10-30 \mathrm{~Hz}$ and 30-49 Hz of geophone X channel and in all four analyzed ranges of hydrophone №1. The signal did not manifest in the range of $52-99 \mathrm{~Hz}$ of the geophone.

Fig.7 presents a acoustic signal variations by the microbarometer, the geophone and by the high-frequency geoacoustic signal in autumn 2019 when the source of power supply for all the equipment was changed to the solar electric station. In this case, pulse signals were de- 
tected in all the analyzed ranges of the microbarometer, the geophone and the high-frequency geoacoustic system.

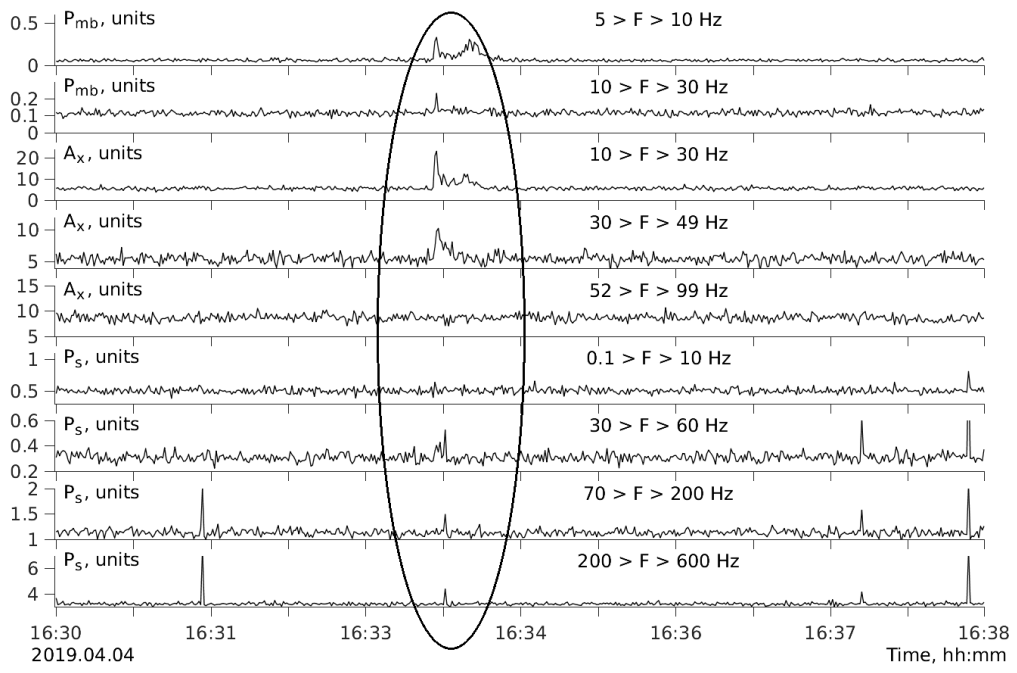

Figure 6: Atmospheric acoustic signal variations $P_{m b}$ recorded by the microbarometer, geoacoustic signal $A_{x}$ recorded by the geophone (X component), geoacoustic signal $P_{s}$ recorded by the hydrophone №1 of high-frequency geoacoustic system from 16:30 to 16:38 UT on April 4, 2019. Ellipse shows the simultaneous amplitude jump

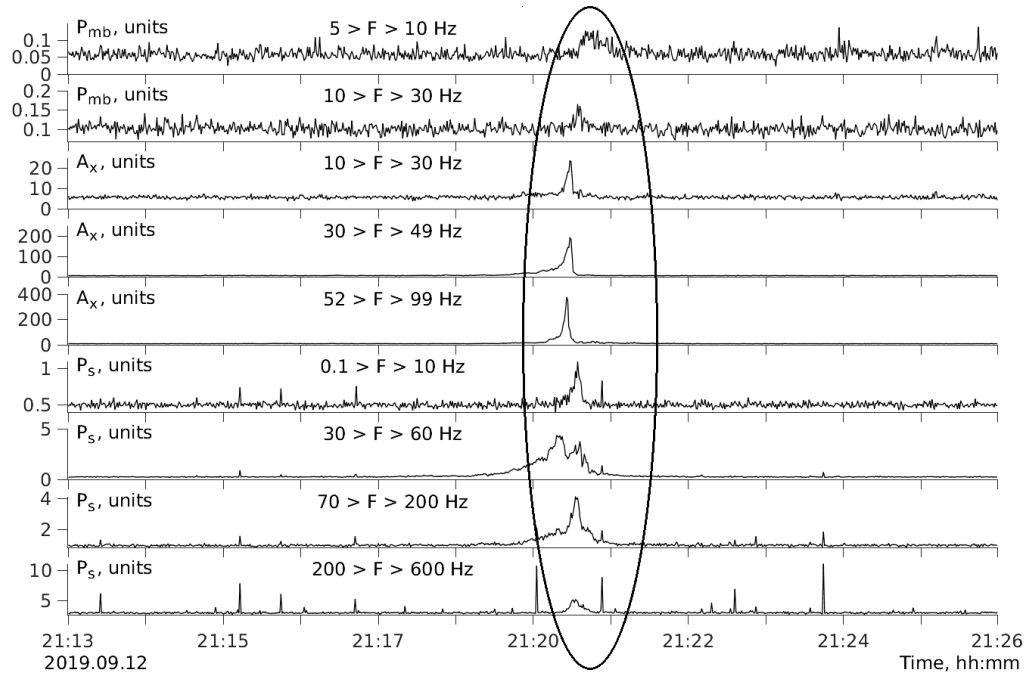

Figure 7: Atmospheric acoustic signal variations $P_{m b}$ recorded by the microbarometer, geoacoustic signal $A_{x}$ recorded by the geophone (X component), geoacoustic signal $P_{s}$ recorded by the hydrophone №1 of high-frequency geoacoustic system from 21:13 to 21:26 UT on September 12, 2019. Ellipse shows the simultaneous amplitude jump 


\section{Conclusions}

Thus, as the result of long-term lithospheric-atmospheric observations in the seismically active region, it was shown that acoustic emission in the range of units-tens of $\mathrm{Hz}$ occurs in the near-surface sedimentary rocks during deformation intensification. It penetrates into the atmosphere and is recorded by the ground surface. Such emission is not affected significantly by season or time of a day. Further direction of the investigation is the detection of possible relation between geoacoutic emission penetrating into the atmosphere and activation of seismotectonic process in the region.

The investigation is of interest for constructing a model of lithosphere-atmosphere relation in the seismically active region.

The work was carried out as part of the implementation of the state task AAAA-A21121011290003-0

\section{References}

[1] Blanc E. Annals of Geophysics 3(5), 673-687 (1985)

[2] Gokhberg M.B., Pilipenko V.A., Pokhotelov O.A. Izvestiya of the Academy of Sciences of the USSR. Physics of the Solid Earth. 10, 17-21 (1983)

[3] Garmash C.B., Lin'kov E.M., Petrova L.N., Shved G.M. Izvestiya of the Academy of Sciences of the USSR. Atmospheric and Oceanic Physics. 25(12), 1290-1299 (1989)

[4] Lin'kov E.M., Petrova L.N., Osipov K.S. Doklady of the USSR Academy of Sciences. 313(5), 1095-1098 (1990)

[5] Goerke V.H., Young J.M., Cook R.K. Jour. Geophys. Research. 70, 6017-6022 (1965)

[6] Firstov P.P., Adushkin V.V., Storcheus A.B. Doklady of the USSR Academy of Sciences. 259(5), 1078-1081 (1978)

[7] Richie W.C., Chick D.R. Journ. Acoust Soc. Amer.41(5), 1377-1378 (1967)

[8] Tseytlin Ya.I., Smoliy H.I. Seismic and shock waves from industrial bursts. - Moscow: Nedra, (1981)

[9] Shalimov S.L. Cosmic Research. 36(5), 542-545 (1998)

[10] Kuznetsov V.V., Plotkin V.V., Khomutov S.Y., Grekhov O.M., Pavlov A.F., Fedorov A.N. Physics and Chemistry of the Earth (A) 25(3), 325-328 (2000)

[11] Kovalevskiy V.V. Acoustical Physics. 51, 92-102 (2005)

[12] Goshdzhanov M., Boltaev D., Karryev A., Kulieva R.N., Mukhanov M.B., Khismatullina N.R. Izvestiya of the Academy of Sciences of the USSR. Physics of the Solid Earth 2, 90-95 (1996)

[13] Afraymovich E.L., Kosogorov E.A., Plotnikov A.B., Uralov A.M. Izvestiya. Physics of the Solid Earth 6, 16-28 (2001)

[14] Al'perovich L.S., Ponomarev E.A., Fedorovich G.V. Izvestiya of the Academy of Sciences of the USSR. Physics of the Solid Earth 11, 9-20 (1985)

[15] Adushkin V.V., Spivak A.A., Kishkina S.B., Loktev D.N., Solovev S.P. Izvestiya. Physics of the Solid Earth 42(7), 567-584 (2006)

[16] Gordienko V.A., Gordienko T.V., Krasnopistsev N.V., Kuptsov A.V., Larionov I.A., Marapulets Yu.V., Shevtsov B.M., Rutenko A.N. Acoustical physics 54(1), 82-93 (2008)

[17] Kuznecov V.V., Plotkin V.V., Homutov S.Yu., Dokl. Earth. Sci. 370(2), 243-248 (2000)

[18] Kuptsov A.V. Izvestiya. Physics of the Solid Earth 41(10), 825-831 (2005)

[19] Marapulets Yu.V., Shevtsov B.M., Larionov I.A., Mishchenko M.A., Shcherbina A.O., Solodchuk A.A. Russian Journal of Pacific Geology 6(6), 457-464 (2012) 
[20] Marapulets Yu.V. Bulletin KRASEC. Phys. and Math. Sci. 10(1), 39-48 (2015)

[21] Larionov I.A., Marapulets Yu.V., Bulletin KRASEC. Phys. and Math. Sci, 26(1), 86-91 (2019)

[22] Larionov I.A., Marapulets Yu.V., Mishchenko M.A, E3S Web of Conferences, 127 (2019), 02023

[23] Larionov I.A., Marapulets Yu.V., Shevtsov B.M. Solid Earth 5, 1293-1300 (2014)

[24] Seysmopriemniki p'ezoelektricheskie A16. Rukovodstvo po ekspluatatsii. 402152.004RE [Piezoelectrical seismometers A16. User manual. 402152.004RE], (ZAO Geoakustica, Moscow, 2006) 40

[25] Mishchenko M.A., Marapulets Yu.V., Larionov I.A., Bogomolov L.M., Sychev V.N. E3S Web of Conferences 62 (2018), 02009

[26] Larionov I.A., Malkin E.I., Marapulets Yu.V., Mishchenko M.A., Solodchuk A.A. Bulletin KRASEC. Phys. and Math. Sci. 24(4), 213-225 (2018) 